\title{
SURGICAL TREATMENT OF CHRONIC GASTRIC AND DUODENAL ULCER
}

\author{
By Rodney Maingot, F.R.C.S. \\ Surgeon, Royal Free Hospitál; Senior Surgeon, Suthend General Hospital
}

Much of the confusion of thought and teaching which now exists regarding the surgical management of patients suffering from chronic gastric and chronic duodenal ulcer arises from the fact that in recent years it has become customary to class these two conditions together as one disease-peptic ulcer.

It is true that chronic gastric and chronic duodenal ulcer have certain features in common ; the early signs and symptoms presented by the two conditions are in many respects similar, the acid gastric chyme plays an all-important role in the perpetuation of the lesions, and the medical measures advocated for their treatment are almost identical.

Nevertheless, the risk of malignant transformation, the degree of morbidity and the potentialities of disaster with the accompanying economic disturbances are factors which differ widely according to whether they are associated with chronic duodenal ulcer or with chronic ulcer of the stomach.

Cancerous degeneration of a duodenal ulcer is such a rare event as to constitute a pathological curiosity, but the malignant transformation of a gastric ulcer is a potent factor to be reckoned with in treatment, and is indeed an ever-present menace which cannot be ignored.

The surgical treatment of these two diseases also varies in many important details, and it is for these reasons in particular that I propose to discuss them separately.

\section{(A) Ghronic Gastric Ulcer \\ (1) Indications for Operation}

The main indications for operative interference may be detailed as follows :-

(a) Acute perforation.

(b) Intermittent or continuous haemorrhage arising from the base of a chronic gastric ulcer which efficient medical measures are incapable of arresting.

(c) Anatomical organic deformity of the stomach due to stenosing ulceration and associated with progressive loss of weight; (i) hour-glass stomach ; and (ii) pyloric obstruction.

(d) Failure of healing of the ulcer despite prolonged (four-eight weeks) and well-supervised inpatient medical treatment.

(e) Recurrence of ulceration following (i) one or more courses of in-patient medical treatment ; (ii) simple suture of an acute perforation ; (iii) wedgeor V-excision of the ulcer or other type of unsuitable operation ; or (iv) transgastric transfixion and obliteration by sutures of the ulcer crater to control severe haemorrhage.

(f) Multiple chronic gastric ulcers or combined gastric and duodenal ulcer.

(g) The suspicion of malignancy which cannot be excluded by combined clinical, biochemical, radiological and gastroscopic examination.

(h) The patient is 60 years of age or over, having an ulcerating lesion in the stomach, and giving' a short history of dyspepsia.

(i) Ulcers situated on or about the greater curvature of the stomach or in the pyloric region.

(j) A large gastric ulcer which has penetrated deeply into the substance of the pancreas or liver.

(k) Expedient circumstances and economic reasons in certain instances, e.g., indigent patients, mental cases with callous lesions, etc.

\section{(2) Some Factors Influencing the Choice of Treatment}

Every patient is subjected to the same routine clinical methods of investigation, and if the presence of an ulcer in the stomach has been demonstrated by means of X-rays, and in certain cases by gastroscopy, the physician and surgeon should meet in consultation and decide the method of treatment to be undertaken. The following factors will influence the choice of treatment :-

(a) Hour-Glass Deformity. This lesion, which is due to a stenosing ulcer of the stomach, is extremely rare in men (about 2 per cent.) and seldom responds to medical therapy. In the absence of other contra-indications gastric resection is the best form of treatment. 
In women it is conceivable that medical treatment, or rather stringent dietetic measures, may maintain a state of nutrition compatible with tolerable health if on healing the ulcer has left a small but adequate channel for the passage of food. But the majority of such patients are elderly or have suffered from dyspepsia for many years and have become chronic invalids; sooner or later partial gastrectomy (for choice) or gastro-gastrostomy (when gastric resection is not feasible) must be performed to overcome the effects of obstruction.

I would regard hour-glass deformity associated with progressive loss of weight and strength as a definite indication for operative interference at any age, and I have successfully performed partial gastrectomy (under local anaesthesia) upon patients who were aged $71,75,78$ and 81 respectively, with good immediate and late results.

(b) The Age of the Patient. With Roscoe Graham (1937) and other surgeons', I have so far failed to find a simple chronic gastric ulcer which has not been accompanied by clinical évidence of its presence in a patient under 60 years of age. In other words, I believe that all gastric ulcers which make their appearance after 60 years of age are ulcerating carcinomata, and the patient should be advised to have a partial or subtotal gastrectomy performed as soon as adequate pre-operative preparation permits.

Patients under the age of 40 who give a relatively short history of ulcer and who on barium meal $\mathrm{X}$-ray examination are found to have a small niche on the vertical portion of the lesser curvature are best treated medically. Patients who show a satisfactory response to medical therapy should be examined at intervals over a period of some years to ensure that the healed area in the stomach is staunch.

Aged and infirm patients respond poorly to medical measures, but the risks of operative interference may be considerable. Each case has to be judged on its own merits, but the bias would, on the whole, be in favour of medical treatment.

(c) Sex. The proportion of men to women suffering from gastric ulcer is about three to one, but gastric resection is called for in approximately four times as many men as women. There is, however, considerable variation in these proportions in different parts of Great Britain and even in different quarters of any large city. My experience has been that malignant degeneration of a gastric ulcer is commoner in women than in men.

(d) The Position of the Ulcer. It is frequently stated that ulcers situated on or nearr the greater curvature of the stomach or in the pyloric region are cornmonly malignant in character, and that they require surgical attention as soon as they are diagnosed. Matthews (I935), who described two personal cases and analysed I39, voices the opinion held by most surgeons. He writes :

' Ulcers of the greater curvature produce no characteristic symptoms distinguishing them from other peptic ulcers. There is no certain method of determining whether a lesion found on the greater curvature is benign or malignant, except by histological examination. A review of the cases described illustrates how difficult it may be to differentiate this type of peptic ulcer from carcinoma.'

Simple ulcers of the greater curvature are rare, and less than 200 cases have been reported to date. As these lesions are easily visualized on gastroscopy and on barium meal X-ray examination, their response to the therapeutic test can be closely observed.

In a personal series of six cases of chronic ulcer of the greater curvature, four were subjected to gastric resection, and the microscopic examination of the lesions proved that two were innocent and two were malignant. In the other two cases, as the clinical, radiological and (in one case) gastroscopic evidence supported the diagnosis of simple ulceration, medical treatment was given a tria which proved to be successful, as the ulcer ap peared to be healed soundly in each case withiff six weeks. Subsequent examinations of these cases has shown the healing to be satisfactory.

Ulcers of the greater curvature should be treated on their merits. If the presence of malignancy cannot be ruled out after expert investigation, or if the crater stubbornly refuses to shrink following a course of intensive medical treatment, then it is wiser and safer to operate than to wait and see. In my opinion, the majority of ulcerating lesions of the greater curvature can , be diagnosed accurately by modern methods, and I consider that the incidence of malignancy in circumscribed lesions in this particular part of the stomach has been exaggerated. I do, however, believe with Holmes and Hampton (1932) and Finsterer (1934) that gastro-duodenal resection is the best form of treatment for chronic ulcers of the pyloric region, as they are frequently cancerous in nature, leisurely or obstinate in their response to medical therapy, 'and a cause-though by no means the commonest - of pyloric obstruction.

When this area is the seat of a small destructive lesion visualization through a gastroscope is often impossible or fleeting at best; serial X-ray pictures of the belladonna- and barium-filled writhing spastic gastric outlet usually fail to demonstrate the niche, the meniscus, or the telltale filling defect ; and the clinical picture, is that of a low-grade or established obstruction with its 
accompanying cramp-like epigastric pain, vomiting, dehydration and decline in weight.

(e) The Presence of Multiple Chronic Ulcers in the Stomach as well as the Combination of Gastric Ulcer plus Duodenal Ulcer. It is generally agreed that, where found, such combinations are sufficient to warrant surgical measures.

I once performed subtotal gastrectomy upon a patient who had two chronic ulcers in the stomach, one being situated on the lesser curvature about the incisura, and the other directly opposite on the greater curvature. The lesser-curve ulcer was benign, but on the greater curvature was an ulcerating carcinoma.

Multiple chronic gastric ulcers are seen in about 3 per cent. of resected stomachs, whilst chronic gastric ulcer is associated with a chronic duodenal ulcer in some 12 per cent. of the cases subjected to operation.

(f) The Size of the Ulcer. It was hoped at one time that the size of the ulcer as revealed on barium meal X-ray examination and/or on gastroscopy might be a good index of its character. It is true that the majority of ulcers over one inch in diameter are carcinomata while most of the smaller ulcers prove to be innocent. There are, however, so many exceptions to this general rule that it is almost valueless as a guide to treatment in the individual case.

The large gastric ulcer which has breached all the coats of the stomach and the base of which lies deeply in the substance of the pancreas or liver may, of course, be the seat of malignant transformation. Such ulcers, nevertheless, sometimes show remarkable powers of recuperation and retrogression on gastric intubation, which provides rest to the inflamed organ whilst the nourishment and strength of the patient are maintained (Freeman, 1944).

Relapses or rather recurrence of ulceration following a course of ' home treatment' are the rule. The large penetrating gastric ulcer is not a surgical emergency. Many of the deaths following gastric resection for such ulcers are due to a lack of generalship on the part of the surgeon; to hasty pre-operative management ; to insufficient rehabilitation of the patient; and to the performance of a major surgical undertaking on a viscus which is friable and sodden with inflammatory products.

These cases demand prolonged hospitalization ; continuous feeding through an indwelling Ryle tube employing the milk-drip method; the systematic administration of alkaline draughts ; sedative drugs; the essential vitamins in full dosage ; transfusion of blood before, during and after operation; periodic screening of the ulcerated zone to determine the response to the treatment which has been given; and the selection of the optimum time for operation, namely, when the lesion appears to be healing satisfactorily and the patient's general condition shows an all-round improvement.

On occasion the irremovable duodenal ulcer is encounted on coeliotomy, but intubation and feeding through a Ryle tube, sustained for some weeks, have rendered all-or nearly all-gastric ulcers resectable.

(g) Response to Medical Treatment. Every patient with an active gastric ulcer should, ideally, be investigated and treated as an in-patient in a well-equipped hospital or clinic. But in this country there are not at present sufficient hospital beds available to treat all patients on these lines.

The medical treatment of ulcer of the stomach is a social, psychological, economic, and dietetic problem. Many patients cannot afford the time and expense incurred by prolonged hospitalization, and the majority, owing to nervous tension, anxiety about the future, and worry concerning family affairs, are unable or unwilling to give their full, whole-hearted co-operation. To be successful, medical treatment must be thorough, prolonged, well-supervised, and conducted by one who has made a special study of this subject. Some ulcers will not heal even under the best therapy ; they are indolent or malignant and call for surgical enquiry. Others, on the other hand, heal soundly, as can be proved by periodical gastroscopic and radiological examination. Active treatment must be continued until healing is complete and final ; the risk of recurrence is a very real one, and it may be emphasized here that the majority of so-called recurrences are not, in fact, recurrences at all, but lesions which have never completely healed.

It is now generally accepted that complete disappearance of symptoms with a gain in weight when the patient is subjected to medical treatment is no evidence that the ulcer is benign, since a cancerous gastric lesion will, on occasion, respond in this manner when it presents irrefutable X-ray evidence of its malignancy. The disappearance of the crater as shown on X-ray films, although a favourable sign, does not necessarily imply that the ulcer has healed. The crater may at times become obliterated by exuberant cancer cells which have tipped over into the niche from the malignant margin, or it may be temporarily filled with poorly-nourished, oedematous granulation tissue which has made a brave but ephemeral attempt at bridging the gap. It is also by no means exceptional to find on gastroscopy that the ulcer has healed well, but that months later a sinister mound of actively-growing carcinoma cells has arisen from 
the ill-fated scarred area in the stomach to threaten the life of the patient.

Surgery will therefore be called for in the great majority of patients suffering from chronic gastric ulcer. The case which appears to respond satisfactorily to medical management should be carefully followed up over a long period, as the chances of recurrence of ulceration are great. When recurrence does take place it is almost impossible pre-operatively to exclude, by the means at our disposal, the possibility of cancerous change in the margin of the ulcer.

\section{(3) Choice of Operation}

(a) Acute Perforation of a Gastric Ulcer. The object of operation in acute perforation is to save the patient's life by a simple expeditious procedure. The operation which fulfils this requirement is simple suture by the method advocated by Roscoe Graham (1937). Three sutures are passed, one through the margins of the hole in the stomach, one above and one below. Then, after drawing a generous amount of great omentum over the perforation, the sutures are securely tied, thus effectively sealing off the puncture. Operations such as excision of the ulcer, gastro-jejunostomy, or partial gastrectomy, should not, in my opinion, be performed in the presence of this catastrophe. If later, however, in the quiescent period of medical treatment the ulcer proves refractory, as it does in a fairly large proportion of such cases, then the claims of gastric resection will have to be considered.

(b) Haemorrhage. The prognosis is best in patients under the age of 40 and in women. Medical treatment is instituted in all cases in which massive bleeding from a chronic gastric ulcer occurs. If there is evidence of continued or recurrent haemorrhage after medical therapy has been carried out for 48 hours, it is my view that a surgical attack should be made upon the ulcer without further delay. The patient is given an opportunity to respond to conservative treatment, but if this response is not satisfactory in 48 hours I would advise immediate laparotomy.

The outlook is grave after the age of 50 and in those with large penetrating lesions. When operation is indicated the surgeon has a choice of two procedures: (i) detaching the ulcer from its sclerotic base and closing the hole in the stomach ; or (ii) performing partial gastrectomy. The former operation is reserved for the desperate case and the latter for the expert.

(c) Hour-Glass Stomach. Gastro-gastrostomy, i.e., anastomosis of the proximal and the distal pouches of the stomach, is a simple, effective operation which should be carried out in frail elderly subjects when the isthmus is situated high up in the stomach and the patient is obviously not fit enough to withstand the ordeal of gastric re- $\stackrel{\mathbb{Q}}{\stackrel{2}{2}}$ section. In most cases, however, partial gastrec- $c$. tomy, performed under local or cyclopropane $\overrightarrow{\vec{F}}$ anaesthesia, is a safe and satisfactory procedure $\stackrel{0}{?}$ associated with a low death-rate.

(d) Chronic Gastric Ulcer or Ulcer-Cancer. During the last 50 years a large number of operations have been recommended for the unresponsive gastric ulcer and I have practised most of them at one time or another. During the last ten years I $\overrightarrow{0}$ have abandoned the following operations, as the immediate or late results were unsatisfactory in a high proportion of the cases : (i) excision alone ; (ii) gastro-jejunostomy alone (von Hacker); (iii) wedge- or V-excision of the ulcer followed by gastro-jejunostomy ; (iv) cautery excision or destruction of the ulcer followed by gastrojejunostomy (Balfour) ; (v) segmental or sleeve resection (Riedel-Rodman); (vi) excision of a pyloric ulcer combined with pyloroplasty (Judd) ; (vii) partial gastric exclusion (Devine); (viii) cholecysto-gastrostomy (Braithwaite); and (ix) jejunostomy.

I have, in a previous issue of this Journal (1942) and in my work 'Abdominal Operations 0 (1940), set forth at some length the reasong $\stackrel{+}{\infty}$ which led me to abandon all of the procedure enumerated above.

Following the advice of Allen, Cave, Waltman Walters, Lahey and other surgeons, vagotomy should not be employed in the treatment of chronic gastric ulcer.

Dockerty, of the Mayo Clinic, told me that 18 per cent. of the gastrectomy specimens referred to him and diagnosed macroscopically as simple peptic ulcer proved on microscopic investigation (of a large number of serial sections) to be undergoing malignant change in the margin of the ulcer.

When we operate for chronic ulcer of the stomach we should do so as for cancer of this organ. I do not know what percentage of gastric ulcers undergo malignant change or what proportion of lesions diagnosed as gastric ulcer are, in fact, ulcerating carcinomata. But I do know that if operation is undertaken only on those cases which prove unresponsive to stringent medical treatment or on neglected cases with sizeable lesions, the microscope will reveal the presence of cancer cells in some 10-20 per cent. of cases.

A study of 50 of my own gastrectomy specimens (women only) showed 'ulcer-cancer' or 'ulcerating carcinoma' in $I I$ of the cases diagnosed pre-operatively as chronic peptic ulcer of the stomach.

The operation of choice for suspected ulcercancer, indolent ulcer or recurrent ulcer is sub- 
total gastrectomy by one of the following methods : (i) anterior Polya-Hofmeister ; (ii) posterior PolyaHofmeister ; (iii) Billroth I types-Finochietto's for preference.

The anterior Polya-Hofmeister operation, which has been carried out in 90 per cent. of my cases, is the one of choice for the following reasons : (i) the anastomosis is readily performed near the accessible greater curvature by construction of a Hofmeister valve ; (ii) post-operative obstructive symptoms and the sensation of fullness after meals are obviated; (iii) the technique is simple and the mortality under 4 per cent. ; and (iv) in the rare event of jejunal ulceration the implicated viscera are approached with ease.

The posterior Polya-Hofmeister operation may be called for when the mesentery of the jejunum is short or where for some special reason a partial rather than a subtotal gastric resection is indicated. Obstructive symptoms are decidedly more common with the posterior operation, due perhaps partly to the proximal and distal jejunal limbs becoming tethered together in the funnel of retracting mesocolon.

The technical beauty of Finochietto's modification of the Billroth I method has always appealed to me, and when I am constrained to perform an axial anastomosis between the cut ends of stomach and duodenum I choose this procedure. The Billroth I operation is indicated in feeble senile patients; where the infracolic compartment is shrouded in adhesions (the aftermath of a previous peritonitis); or where the supporting structures of duodeno-jejunal flexure show some strange departure from the normal. The Finochietto endto-end union is quick, limited to the supracolic compartment, associated with little if any shock, and has a low death-rate (3 per cent.) even in debilitated subjects. It has one drawback-a flaw common to all the Billroth I methods-regurgitation of bile into the mouth. Nausea after meals, the occasional stricture at the anastomotic junction, a sense of oppression in the epigastric region after meals, the taste of gall or acid in the mouth-more especially when the patient is recumbent-are some of the unpleasant features which restrict the use of this otherwise attractive operation.

\section{(4) The Technique of the Operation}

A scheme of pre- and post-operative nursing for subtotal gastrectomy cases is outlined at the end of this chapter.

(a) Ante-colic or Anterior Polya-Hofmeister Subtotal Gastrectomy

Incision. There is a choice of five incisions : mid-line, left paramedian, left vertical transrectal muscle-splitting, left oblique and transverse. All these incisions have their good and bad points.
In cases of gastric ulcer the choice lies between a lengthy left subcostal incision and a vertical left transrectal muscle-splitting incision. The former commences near the tip of the right costal cartilage and extends across the epigastrium just below the xiphisternum before sweeping downwards one inch below the left costal margin to the outer border of the rectus muscle. A portion of the right rectus muscle is divided and the whole of the left rectus, together with the anterior and posterior sheaths of the muscle and peritoneum, is cut across obliquely close to the left costal margin.

This incision gives an excellent exposure of the body of the stomach, the fundus and cardia, and greatly simplifies the operation of radical excision of the stomach.

The wound is closed in layers, using long strands of No. O medium chromic catgut for the continuous sutures. A few mattress sutures are placed in the posterior sheath to draw together the cut margins before the continuous suture is inserted. The edges of the wound are approximated with vertical mattress' sutures of fine black silk. The vertical muscle-splitting incision gives a good exposure and is easy to close securely. I have been employing this incision more and more during the last few years.

Exploration of the Abdomen. In all cases a thorough exploration of all the abdominal viscera is conducted. The upper abdominal organs are inspected by sight and touch, but the lower are examined only with the palpating hand. The whole stomach-anterior and posterior wall, duodenum, pancreas, spleen, liver, gall-bladder and biliary passages, mesocolon, duodeno-jejunal flexure, proximal loop of jejunum and the mesojejunum, must be carefully scrutinized before deciding upon the scope of the operation.

If the ligament of Treitz appears to be anomalous, if the first loop of jejunum is caught up in scar tissue, or if the infracolic compartment is enmeshed in adhesions, it is far wiser to perform a Billroth I operation than to persevere with a Polya type of resection and anastomosis in the face of these obstacles.

A small gastric ulcer or an ulcer which appears almost to have healed does not imply the need for a small operation, e.g., simple excision. The size of the ulcer must not influence the choice of operation, for once we are committed to operation for a chronic gastric ulcer which has defied medical treatment the only procedure that can be countenanced is gastric resection. The presence of infracolic adhesions or the combination of a gastric ulcer with a penetrating duodenal ulcer may influence the choice of anastomosis, but does not alter the fundamental principle that the best and safest method of dealing with an ulcer of the stomach 
consists in removing it together with at least fivesixths of the viscus.

Mobilization of the Stomach and Duodenum. The great omentum and transverse colon are drawn through the wound and covered with large warm moist pads. Then, after the gastrocolic ligament has been put on the stretch and an avascular area chosen well to the left of the greater curvature, a wide opening into the lesser sac is obtained by tearing the omentum apart with the fingers (Fig. I).

After dissecting free with scissors any adhesions which are found in the lesser sac between the upper leaf of mesocolon and the posterior aspect of the stomach, or possibly between the ulcer and the mesocolon, and after freeing the middle colic and possibly the arching branch of the right colic artery from its fibrinous attachments to the pyloric zone, a large warm swab is packed into the stomach bed to keep these vulnerable vessels out of harm's way. A good view of the ulcer, or rather of its posterior anchorage and its relations to the middle colic artery, can thus be obtained.

In some cases, as in the operation for cancer of the stomach, the major part of the omentum is detached from the colon and left hanging attached to the greater curvature ; . but in most gastric resections for simple ulcer the blood vessels which spring from the inferior border of the curving right gastro-epiploic artery are isolated, clipped, divided, and tied off with No. 4 silk, one by one, until the lower border of the pylorus is reached (Fig. 2).

The right gastro-epiploic vessels are ligatured and divided where they come into view beneath the antrum, the right gastric artery is underrun and tied off securely, the first part of the duodenum freely mobilized and clamped with two Parker-Kerr forceps just distal to the sphincteric ring, and the gut divided with a carbolized knife between the two clamps (Figs. 3 and 4 ).

The blades of the Parker-Kerr forceps which embrace the short segment of duodenum close to the pylorus are immediately covered by a special metal sheath which is well illustrated in Fig. 4.

The stomach is drawn over the left side of the chest out of the operative field for the time being, and is surrounded with warm, moist abdominal packs. The duodenal stump is now closed in a Connell suture or sewing-machine stitch of No. 2 silk reinforced with a series of interrupted mattress sutures of fine silk, or in the simple manner depicted in Fig. 5. I often place the sutured duodenum retroperitoneally by attaching the capsule of the pancreas to the anterior wall of the duodenum or, as an added precaution, cover the closed stump with a pad of fatty omentum.

The stomach is picked up again and held well over to the patient's right side, while an assistant firmly retracts the left margin of the abdominat wound. This manoeuvre brings the spleen an\& the left portion of the great omentum containing the branching gastro-epiploic vessels into viewes Care must be taken at this stage to avoid tearing the capsule of the friable spleen by vigorous retraction with the Deaver's retractor or by pulling to forcibly on the great omentum or on the gastro $\Phi$ splenic omentum itself.

All the remaining blood vessels along the greatef. curvature of the stomach up to the main vasculaP pedicle of the spleen are isolated, clipped with haemostats, divided and ligatured seriatim. Im performing subtotal gastrectomy it is necessary to detach the lower half or more of the filmy gastro 3 . splenic omentum.

When the ulcer deeply pits the pancreas or liver after isolating the operative field with Lahey' Cellophane squares, the stomach is cut adrift cautiously from its moorings with a cautery, the pearly-white sclerotic base is coagulated with of diathermy disk or button, and the hole in the stomach wall is closed with a purse-string suture of strong silk. The now leathery ' cooked' base of the crater is cleansed or mopped with penicillin? cream.

The left gastric artery must now be displaze close to its origin, tied off in continuity about क्षेत् in. below the oesophagus, and divided betweers ligatures of No. 4 silk. Fig. 6 shows how this mas be done by insinuating a pair of dissecting forcep\$ between the lesser curvature and the large vessels coursing vipwards in the gastrohepatic omentum $\vec{F}$

As soon as the right gastric vessels have beers ligated the raw surface which remains on the lesser curve is reperitonealized (Fig. 6).

Resection of Stomach and Gastro-fejuna Anastomosis. At this point in the operation Allis forceps are applied to the lesser and greate curvatures to act as markers before the large strong, thin-bladed Payr clamp is crushed homes obliquely across the stomach. The first marker is clipped to the reperitonealized lesser curvature about 2 in. below the oesophagus, the second pair of Allis forceps is applied high up on the greate curvature, and the Payr clamp is locked in position precisely above these markers.

Upward traction is now made on the Payr clamps in order to draw the posterior aspect of the stomaches into the wound whilst the redundant portion of the organ beyond the blades of the enterotome is surrounded with abdominal pads and laid on the left side of the patient's chest.

The stomach is now prepared for anastomosis to the proximal jejunum, and the Hofmeister valve? is fashioned. A portion of the stomach at leas $\mathbb{D}$ three finger-breadths in length towards the 
greater curvature is reserved for the stoma, and the part towards the lesser curvature is undersewn, divided and inturned. A straight, short, round-bodied needle, threaded with a strand of No. 3 silk, is passed beneath the Payr clamp, through both walls of the stomach about $\frac{1}{8}$ in. from the free margin of the lesser curvature. The suture is then tied, and that part of the gastric wall embraced by the suture is cut free, the blade of the knife being kept close to the under-surface of the clamp (Fig. 7).

This procedure is repeated again and again until a sufficient amount of stomach towards the lesser curvature has been cut adrift and an adequate amount $\left(2 \frac{1}{2}-3\right.$ in.) remains suspended from the clamp for the gastro-jejunal stoma which will shortly be constructed (Fig. 8). Alternatively, the upper portion of the stomach embraced in the Payr clamp may be securely closed by a Shoulders' machine stitch, after which the small portion of stomach between this stitch and the Payr clamp is cut through with a knife. The new lesser curvature from the ligature on the left gastric artery to the Payr clamp is next completely invaginated by a series of closely-placed mattress or cross sutures of No. I silk mounted on small half-circle needles.

A circular incision is made precisely below the Payr enterotome through the posterior and anterior seromuscular layers of the small gastric tube down to the submucosa in order to expose, isolate and individually under-run and ligate all the blood vessels which are seen coursing upwards towards the clamp (Fig. 9). The blood vessels in the anterior wall are more numerous and larger than those on the posterior wall of the stomach.

The great omentum and transverse colon are held upwards and the duodeno-jejunal flexure is identified by sight, and a long loop of proximal jejunum is drawn into the wound. After packing the great omentum and the transverse colon into the empty stomach bed and beneath the overhanging right lobe of the liver, the proximal jejunum close to the duodeno-jejunal flexure is drawn across the transverse colon and applied to the ligated stump of the left gastric artery and a portion of jejunum some 6-8 in. beyond this point is selected for anastomosis to the gastric pouch. The length of taut jejunum from the duodenojejunal flexure to the ligated stump of the left gastric artery is variable $(=x)$, as it will depend upon the amount of stomach resected, but it usually measures about 2 in. If we allow a further 6-8 in. for slack at the duodeno-jejunal flexure and in the portion of bowel proximal to the reconstructed lesser curvature, and also for upward retraction of the gastric pouch when the anastomosis is completed, the loop stretching from the flexure to a point some 2 in. below the right border of the cardiac orifice will take a graceful S-shaped curve for 8-10 in. (=x plus 6-8 in.).

The stoma itself will be a further $2-3$ in. beyond in the descending limb of jejunum (see Fig. 13). The loop is therefore a long one, is antecolic, is made to swing from right to left in the reverse direction to that recommended by Moynihan, Lahey and Pannett, and the opening is placed towards the greater curvature. The afferent jejunum is buttressed against the new lesser curvature, thus reinforcing the valve, after which the intestine, $\frac{1}{2}$ in. from its mesenteric attachment, is fixed with fine silk stitches to the posterior aspect of the stomach, $\frac{1}{4}$ in. away from the seromuscular groove.

A Cushing right-angled continuous posterior seromuscular suture of No. $\infty 0$ medium chromic catgut mounted on an eyeless needle is next introduced, uniting the contiguous margins of the stomach and jejunum from the greater to the lesser curvature (Fig. 9).

The stomach contents are aspirated through the indwelling Ryle tube which was passed before operation and which will be allowed to remain in situ for a day or two after operation. The seromuscular coats of jejunum are then incised longitudinally and $\frac{1}{4}$ in. away from the Cushing suture (Fig. 9), and any sizeable blood vessels which are seen lying on the submucosa are underrun and ligated with the finest silk. The exposed mucous membrane of the jejunum is picked up and incised, and the intestinal contents are aspirated with a sucker, after which the stomach is likewise opened posteriorly for the full length of the incision and any remaining gastric chyme removed by suction.

Starting at the greater curvature, the second posterior continuous suture is passed as a lockstitch which evenly approximates the opposing cut margins of the stomach and small bowel (Fig. 10). When this stitch reaches the lesser curvature it is continued anteriorly as a BellSchmieden or in-out in-out suture (Fig. I I). A Connell or loop-on-the-mucosa stitch is also very satisfactory and produces a neat inversion. Traction on the Payr clamp is maintained while the anterior wall of the stomach is divided and almost until the last suture is inserted, thereby facilitating the introduction of the anterior continuous suture which is finally tied to the end that has been kept long (Figs. I I and I2).

The operation is completed by picking up the first posterior suture and introducing this anteriorly as a continuous Lembert suture which invaginates the suture line. When this suture reaches the point where it started at the greater curvature it is tied to the end which has been left long and clipped by a small haemostat. A 
few interrupted sutures of fine silk are introduced at the greater curvature and at any weak or untidy points in the length of the anastomosis.

In order to prevent sagging I reinforce the region of the greater curvature with omentum and also anchor the transverse colon and the afferent curving jejunal loop to the capsule of the pancreas with a few well-placed sutures. Fig. 13 shows the position of the stoma.

\section{Comments on the Operation}

Much of the success of the operation depends upon choosing a suitable length of proximal jejunum and upon applying this to the stomach by the method I have suggested. The valve and the stoma (which should admit about three fingers) should be constructed so that all nourishment introduced into the funnel-shaped stomach is deflected into the distal limb of jejunum and so that no food can find its way into the duodenum, which is rebellious to even a minor degree of distension (Fig. I3).

The anastomosis may be performed by the closed or aseptic method with the Furniss clamp (Culligan, 1944), or on the lines advocated by Wangensteen (1940), Pannett (1945) or Babcock (1942).

It is claimed that the closed (aseptic) method of gastro-jejunal union reduces the incidence of postoperative peritonitis and infection of the wound, shock and the length of time expended on the operation. As, however, the procedure is not truly aseptic and the measures taken to prevent post-operative haemorrhage are not uniformly satisfactory, and as the sutures cannot be introduced with the same precision and security as in the open operation, I seldom resort to the closed technique in gastric operations.

The large Petz clamp may be employed to simplify the fashioning of the gastro-jejunal anastomosis. The Petz instrument is crushed home along the same oblique line of the stomach in its upper fifth or sixth as the Payr clamp. The stomach is then steadied with Allis forceps and a cautery cuts through the crushed groove between the two rows of clips. The upper one-third or so of the crushed rim of the stomach with its contained metallic clips is inverted with a series of Halsted sutures and the portion of the stomach towards the greater curvature is used for the anastomosis. The crushed area with its clips, which mark the extent of the new stoma, must now, of course, be cut away with scissors, after which the gastro-jejunal anastomosis is carried out in the usual manner.

The immediate and late results of the anterior Polya-Hofmeister subtotal gastrectomy are most gratifying; the average post-operative stay in hospital is ten days ; the patients on discharge are allowed full diet without restrictions; they re quire no medical treatment; approximately 98 per cent. are restored to full economic efficiency the subsequent onset of jejunal ulceration is less than 0.5 per cent., and the majority show a definite gain in weight and strength.

The operative death-rate is low. At the May Clinic in 1943 partial gastrectomy was performe on 145 cases with only two deaths (I.4 per cent. ${ }^{\circ}$ (Counseller, 1944), whilst in 1945 of the 148 patients subjected to gastric resection there were but three deaths (2.I per cent.). In a personas series (1938-1942) of 77 cases of subtotal gase trectomy for gastric ulcer there were thre fatalities (3.6 per cent.). In a later series (I943 1945), 6r cases of chronic gastric ulcer were subi jected to subtotal gastrectomy without fatality.

\section{(b) The Posterior Polya-Hofmeister Operation}

The mobilization of the stomach and the closure of the duodenal stump are the same as in theanterior operation. In the posterior operation shorter loop of jejunum is chosen for anastomosis to the stomach (about 5-6 in.), the opening is made in the mesocolon to the left of the middle celio artery, and the margins are sutured all around gastric pouch, thus placing the stomach in क्षेల infracolic compartment of the abdomen. The valve and anastomosis are constructed as described but at the completion of the operation the greateg curvature is deliberately rotated so that it comes to lie anteriorly and the lesser curvature posteriorly thereby permitting the proximal jejunum to pur 3 sue its natural course without any danger of its being kinked or obstructed.

\section{(c) Finochietto's Operation}

Finochietto's method of performing the Bill roth $I$ operation is described in some detail an $\mathrm{B}$. freely illustrated in 'Post-Graduate Surgery' (1936) to which the reader is referred. The essential steps of the operation will, however, bes readily appreciated by studying Fig. I4.

\section{Conclusions}

I. The main indications for operation in cases of gastric ulcer are :

(a) Acute perforation ;

(b) The failure of efficient medical treat? ment ; and

(c) The impossibility of excluding malignancर्रा in certain cases.

2. The operation of choice for chronic gastrico ulcer is the anterior Polya-Hofmeister subtotaP gastrectomy, the details of which are given.

3. The operative mortality of subtotal gas $\frac{\mathbb{D}}{2}$ trectomy in this disease is $2-4$ per cent. 
4. The risks of death from malignant degeneration in a patient with chronic gastric ulcer are greater than those which attend surgical interference.

\section{(B) Chronic Duodenal Ulcer}

The following groups of patients who have chronic duodenal ulcer should receive medical treatment :

I. All those who have uncomplicated ulcers, especially if they have been present for only a short time.

2. All patients 30 years of age or under, unless their lesions are complicated.

3. All older patients whose symptoms are mild and do not impair their efficiency.

4. Any patient whose ulcer is complicated by some medical condition which would render operation hazardous.

5. Psychoneurotic patients who have hyperirritable gastro-intestinal tracts, and whose ulcers are not complicated by deep penetration to the pancreas, repeated haemorrhage or obstruction. I agree with Morlock (1944) who writes :

' One of the essentials leading to success in the medical treatment of any duodenal ulcer is the proper evaluation of the factors which promote the chronicity of the lesion. One of the most important means of determining these is a carefully. detailed history which brings to light not only a chronological record of the development of symptoms but reveals the patient's general family background and personal make-up.'

Again :

'If the symptoms of duodenal ulcer are recognized and treated adequately, satisfactory control can be expected in the majority of cases. Unfortunately, it is still true that 90 per cent. of all duodenal ulcers which lend themselves to control by medical measures are inadequately treated. This inadequacy of treatment results in recurrent ulceration and complications which can be rectified only by surgical measures.'

\section{(1) Indications for Operation}

(a) Acute Perforation.

(b) Intermittent or continuous haemorrhage arising from the base of a chronic duodenal ulcer which medical therapy is incapable of controlling.

(c) Pyloric obstruction due to a long-standing cicatrizing duodenal ulcer.

(d) Failure of efficient medical treatment.

(e) Recurrence of ulceration associated with severe symptoms following: (i)- Simple suture of an acute perforation; (ii) an inadequate operation such as pyloroplasty; (iii) transduodenal transfixion and obliteration by sutures of an ulcer crater to control severe bleeding. (f) Chronic penetrating duodenal ulcer accompanied by a gastric ulcer.

(g) Large penetrating duodenal ulcer which shows no encouraging response to medical therapy (see also (d)).

(h) Expedient circumstances and economic reasons in certain cases.

\section{(2) Some Factors Influencing the Choice of Treatment}

(a) Age. The younger the patient and the shorter the history, the more likely are medical measures to be successful. Medical treatment for elderly patients is usually much less effective than for those who are younger, this being no doubt in part due to the impaired circulation and diminished recuperative powers in the former. Gastro-jejunostomy should not be performed in young patients, i.e., those below the age of 30 , as the incidence of jejunal ulceration following this operation in such patients is more than 35 per cent. The operation of choice in young patients with complicated lesions is gastro-duodenal resection combined with vagotomy.

(b) Sex. Sex does not necessarily influence the choice of treatment, although it should be noted that the mortality following gastric operations in women is lower than it is in men, and the late results are uniformly better in women. This, at least, has been my experience. Again, stomal ulceration is much more rare in women than in men after any type of short-circuiting procedure or gastric resection. Operation for gastric and duodenal ulcer is, of course, much rarer in women than in men.

(c) Length of Ulcer History. The shorter the duration of the disease, the better are the prospects of permanent healing by medical measures. This point at least is undisputed. Patients therefore giving a short history of duodenal ulcer are not good candidates for surgery, and I have no faith in a surgeon who would advise surgical interference in such cases. Patients giving a long history, for example IO-I 5 years, during which time they have undergone many courses of medical treatment for persistent recurrence of symptoms, are best operated upon if no specific contraindications are found to exist.

(d) Pyloric Stenosis. The commonest cause of pyloric stenosis is a cicatrizing duodenal ulcer. We have to distinguish between organic pyloric stenosis and spastic obstruction due to inflammation and oedema around the ulcer. The latter condition is amenable to good medical therapy, the former is not. I used to be taught that pyloric stenosis due to duodenal ulcer was a clear-cut indication for gastro-jejunostomy. Long-standing scar stenosis in an elderly patient with low acid values 
in the gastric juice is an indication for a shortcircuiting operation, but stricture of the duodenum due to chronic ulcer associated with hyperacidity calls for gastric resection.

(e) The Acid Problem. Most of the problems in ulcer management hinge upon the quantity and quality of the hydrochloric acid in the stomach, and it is agreed that operations performed for chronic duodenal ulcer show a far higher percentage of good results in patients with low acidity than in those in whom the acidity is high.

In certain instances, frequent fractional testmeal examinations are of value in helping the surgeon to arrive at a decision as to whether he should perform a short-circuiting operation or a wide resection. But age, the general condition of the patient, and other factors will also have to be taken into account. For example, a young man, say of 30 , with spastic pyloric stenosis due to duodenal ulcer in which test-meal examinations show anacidity or hypochlorhydria may be suffering from a concomitant gastro-duodenitis which appropriate medical measures will quickly circumvent, and re-examination some days later reveal a sharply climbing acid curve. The hyperacidity has in this case been masked by a thick coat of mucus.

Take, for example, the case of an old man of 75 with scar stenosis who is vomiting large quantities of fluid daily, losing weight and slowly starving to death. Here, gastro-jejunostomy performed under local anaesthesia is unquestionably the operation of choice.

Therefore, the acid factor dominates treatment. Gastro-jejunostomy should not be performed upon patients with hyperacidity or upon those under the age of 60 , but should rather be reserved for those over this age with proved hypoacidity or anacidity, for the aged and infirm, and for those who on account of some debilitating disease are unable to withstand the major procedure of gastro-duodenal resection.

\section{(3) The Choice of Operation}

In cases of chronic duodenal ulcer there is a choice of : (i) Gastro-jejunostomy (anterior or posterior) ; (ii) gastrectomy by the Polya-Hofmeister method (anterior or posterior); (iii) Bancroft's procedure followed by subtotal gastrectomy; or (iv) vagotomy alone, vagotomy combined with gastro-jejunostomy, or vagotomy combined with gastric excision.

(a) Acute Perforation of a Duodenal Ulcer. As soon as the diagnosis of acute perforated duodenal ulcer is made, a Ryle tube is passed through the nostril into the stomach and all the gastric contents are aspirated. This prevents any further contamination of the peritoneal cavity. The tube is left in situ during the operation and for the first
two to three post-operative days.

The best operation for acute perforation of $\mathrm{a}^{\mathrm{C}}$. duodenal ulcer is simple suture, and for preference $\vec{\Rightarrow}$ the three-suture method which I have previouslyo described.

In those cases where following simple suture it $\overline{\frac{\partial}{p}}$ is thought that there is some narrowing of the first part of the duodenum, the indwelling stomach tube can be coaxed through the strictured zones into the capacious bowel beyond and be used both $\vec{O}$ for aspiration and for feeding purposes. Another $\vec{\overrightarrow{ }}$ Ryle tube is introduced into the stomach to ensure ${ }_{\sigma}$ that this organ remains completely deflated duringo the first two or three critical days.

In my opinion, gastro-jejunostomy or gastro-i duodenal resection should not be carried out following the performance of simple suture. Wheng the patient is convalescent or some months later: during the tranquil period of medical treatment, $\vec{\omega}$ the case can be reviewed and, if surgery is clearly음 indicated, the appropriate operation can be per- formed under the most favourable conditions.

The majority of perforations diagnosed at

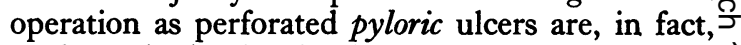
perforated duodenal ulcers. Perforation of gaco pyloric ulcer is an extremely rare event. If all the presumed perforated pyloric ulcers were su医识 jected to barium meal X-ray examination during the period of convalescence, I am convinced that the radiologist would report " deformity of the cap ' in over 90 per cent. of them.

The late results of simple suture of a perforated duodenal ulcer are poor, as over 70 per cent. of the윽 cases have crippling symptoms and fully 50 per cent. of these have eventually to undergo gastric resection or gastro-jejunostomy.

I do not advise conservative (or non-operative)을 treatment for acute perforated duodenal ulcer, as recently revived by Hermon Taylor, Reid, Visick and others.

(b) Bleeding Duodenal Ulcer. The operative treatment of bleeding duodenal ulcer may entailo either partial gastro-duodenal resection or else exposure of the ulcer through an incision in the anterior wall of the duodenum, followed by
transfixion with strong silk sutures.

There is no operation which will afford greater N protection against recurrence of haemorrhage than N resection. When, therefore, the patient can beo operated upon within 48 hours of the onset ofo bleeding, when he appears to be in a satisfactory condition, when the duodenum can be mobilized $\stackrel{\circ}{+}$ and the ulcer is not too large in size or too firmly fixed to the underlying head of the pancreas, partial gastro-duodenal resection should be per- $\stackrel{\Phi}{\Phi}$ formed, the blood-drip being regulated to a steady $\underset{\Omega}{\mathbb{\mathbb { Q }}}$ pace. 

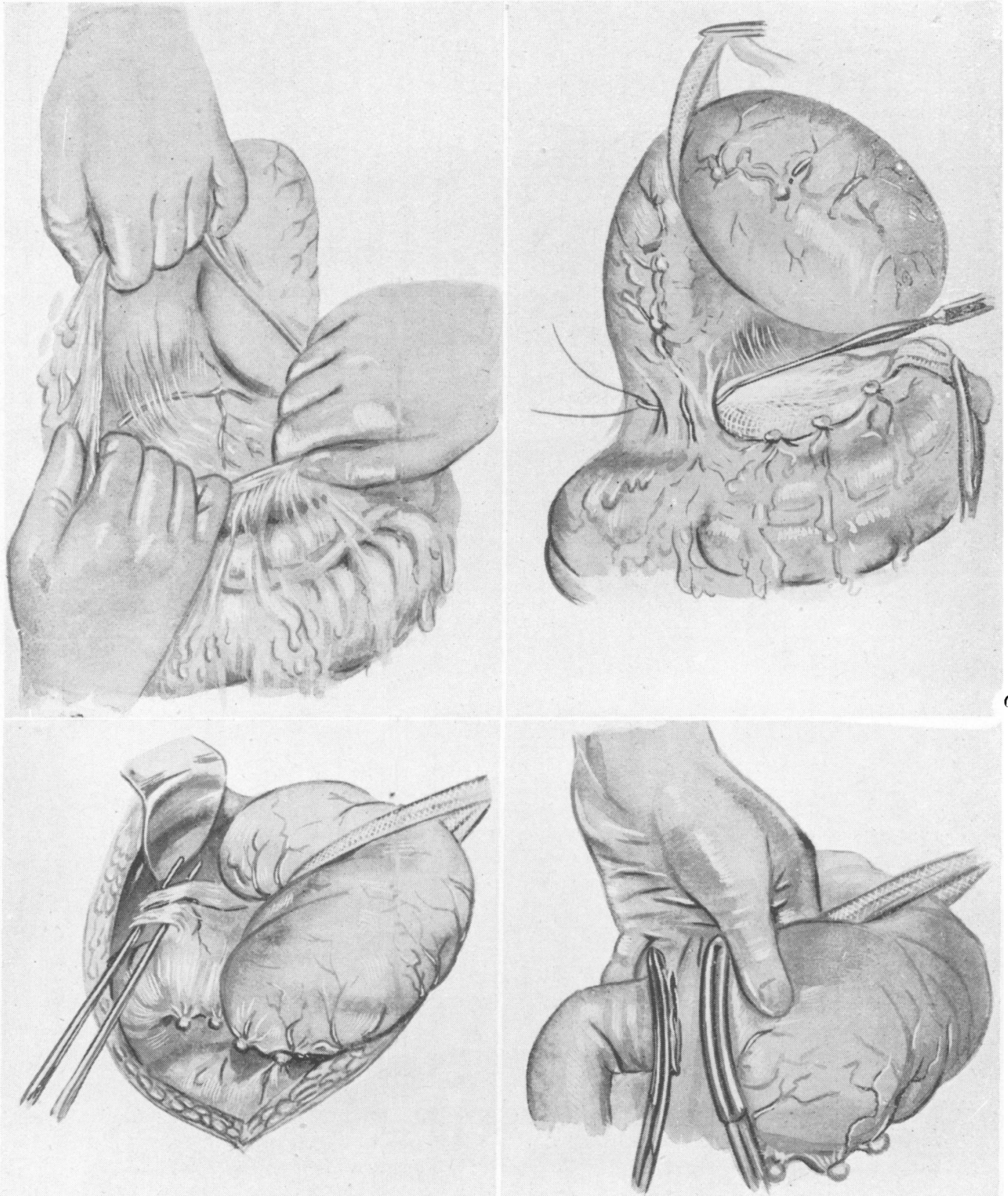

FIG. I.-Polya-Hofmeister Subtotal Gastrectomy. An opening is made into the lesser sac, adhesions between the superior leaf of the mesocolon and the posterior aspect of the pyloric region of the stomach are carefully freed, and the middle colic artery is identified.

Fig. 3.-Polya-Hofmeister Subtotal Gastrectomy. A method of isolating and ligating the right gastriv artery. A pair of long dissecting forceps has been passed between the duodenal wall and the right gastric artery, thus isolating the artery prior to double ligation in continuity. Note also the sling around the stomach, acting as a tractor.

Fig. 2.-Polya-Hofmeister Subtotal Gastrectomy. The blood vessels arising from the convex inferior border of the gastro-epiploic arch are individually isolated, ligatured and tied.

FIG. 4.-Polya-Hofmeister Subtotal Gastrectomy. The duodenum is clamped with two ParkerKerr forceps and divided, and the stump nearest the pylorus is covered with a special guard. 

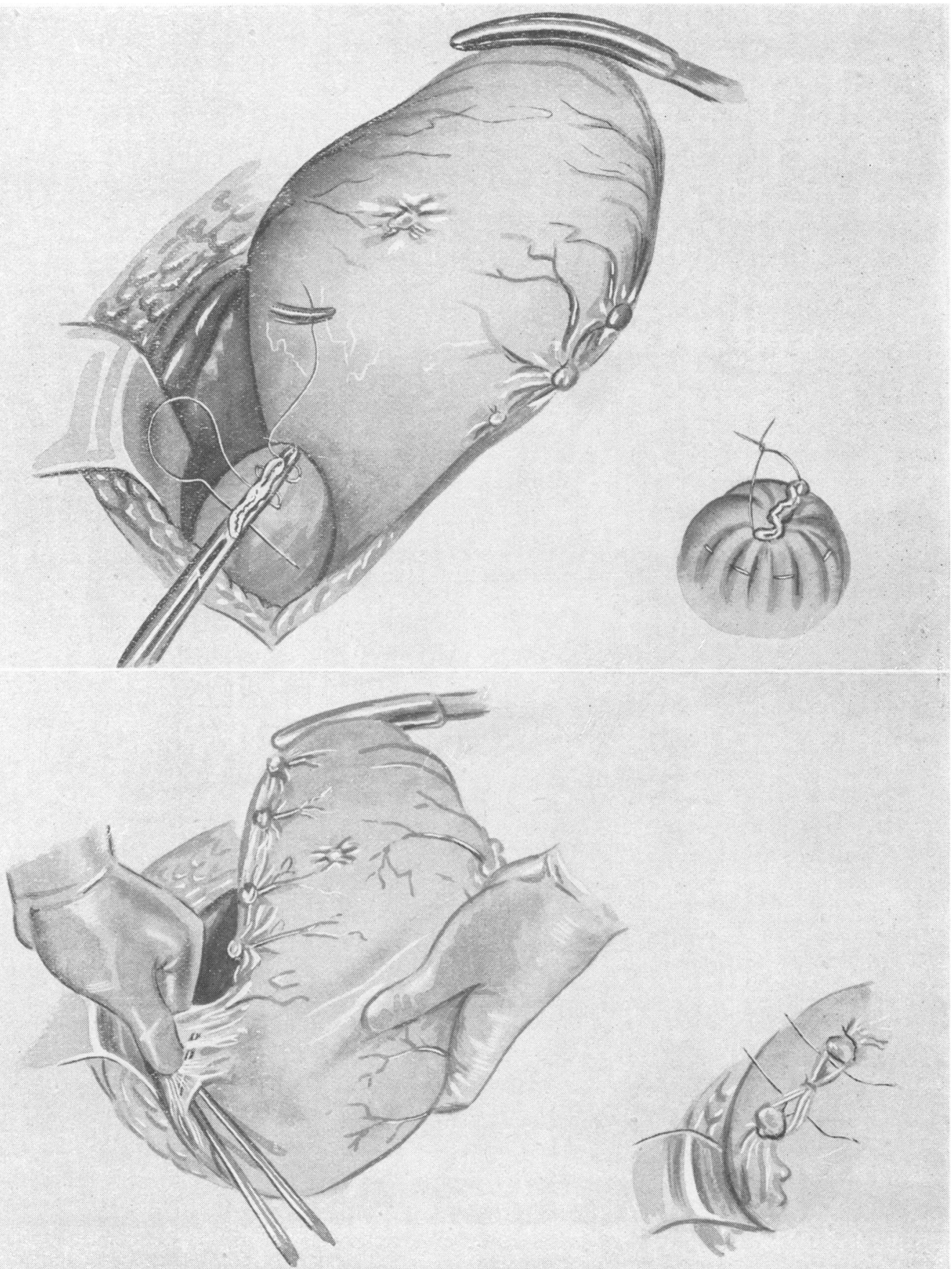

FIG. 5.-Polya-Hofmeister Subtotal Gastrectomy. A method commonly employed for securely closing the duodenal stump.

Fig. 6;-Polya-Hofmeister Subtotal Gastrectomy. Isolation of the left gastric artery prior to ligation. INSET.- The raw surface on the lesser curvature which remains after the left gastric artery has been divided, ligated and is reperitonized. 

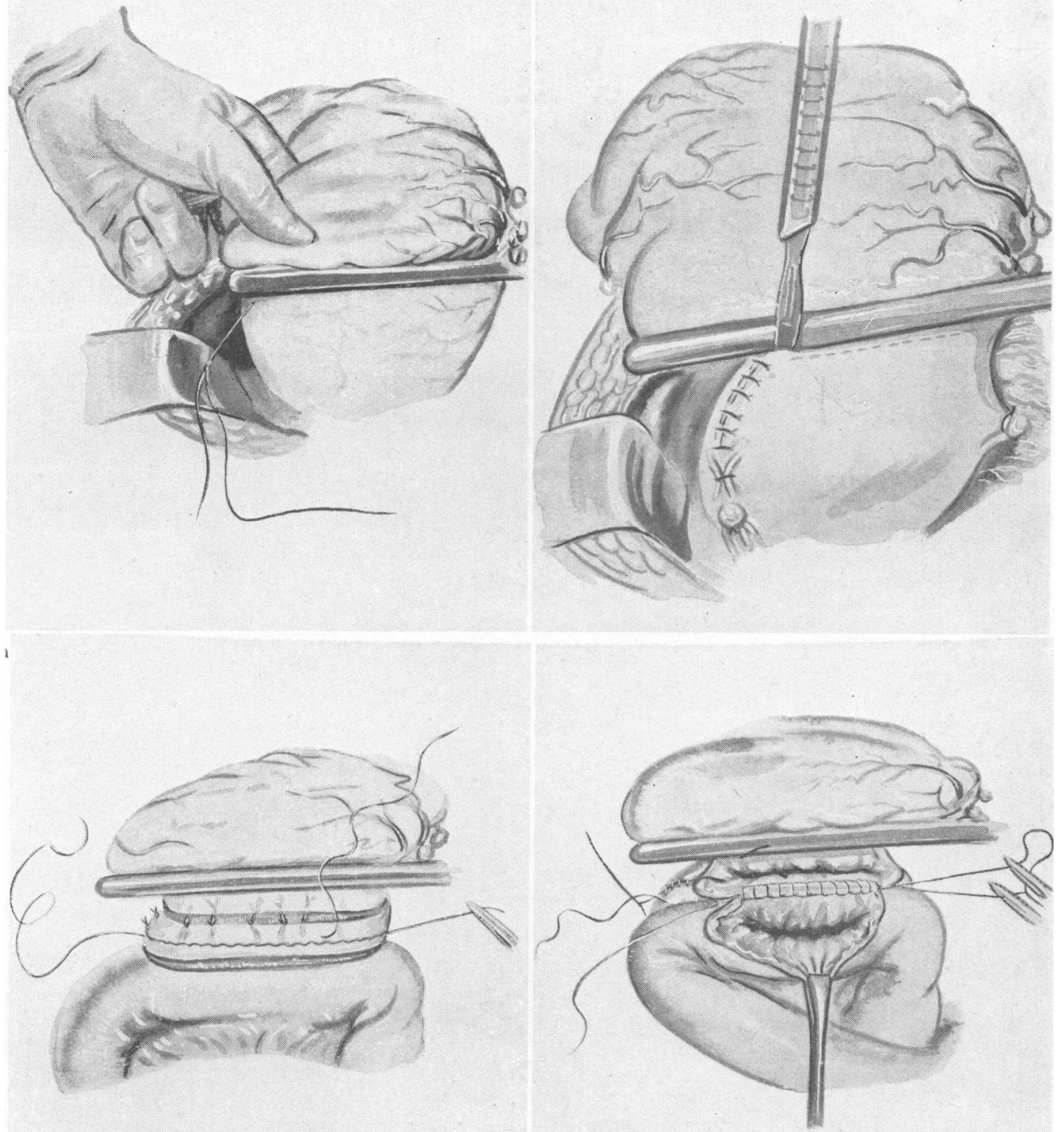

Fig. 7.-Polya-Hofmeister Subtotal Gastrectomy. The Payr clamp has been applied to the stomach. The commencement of the fashioning of the Hofmeister valve. A round-bodied needle threaded with No. 3 silk is passed through both walls of the stomach near the lesser curvature and tied, and the portion of the stomach wall above the ligated area is divided close to the clamp. This manoeuvre is repeated until the right margin of the portion of stomach selected for the stoma is reached.

Fig. 9.-Polya-Hofmeister Subtotal Gastrectomy. The introduction of the Cushing right-angled continuous posterior suture.

Fig. 8.-Polya-Hofmeister Subtotal Gastrectomy. A portion of the stomach towards the lesser curvature has been cut free and sutured. The part towards the greater curvature is about to be employed for the anastomosis.

FIG. 10.-Polya-Hofmeister Subtotal Gastrectomy. The second continuous posterior suture is passed as a lockstitch. 

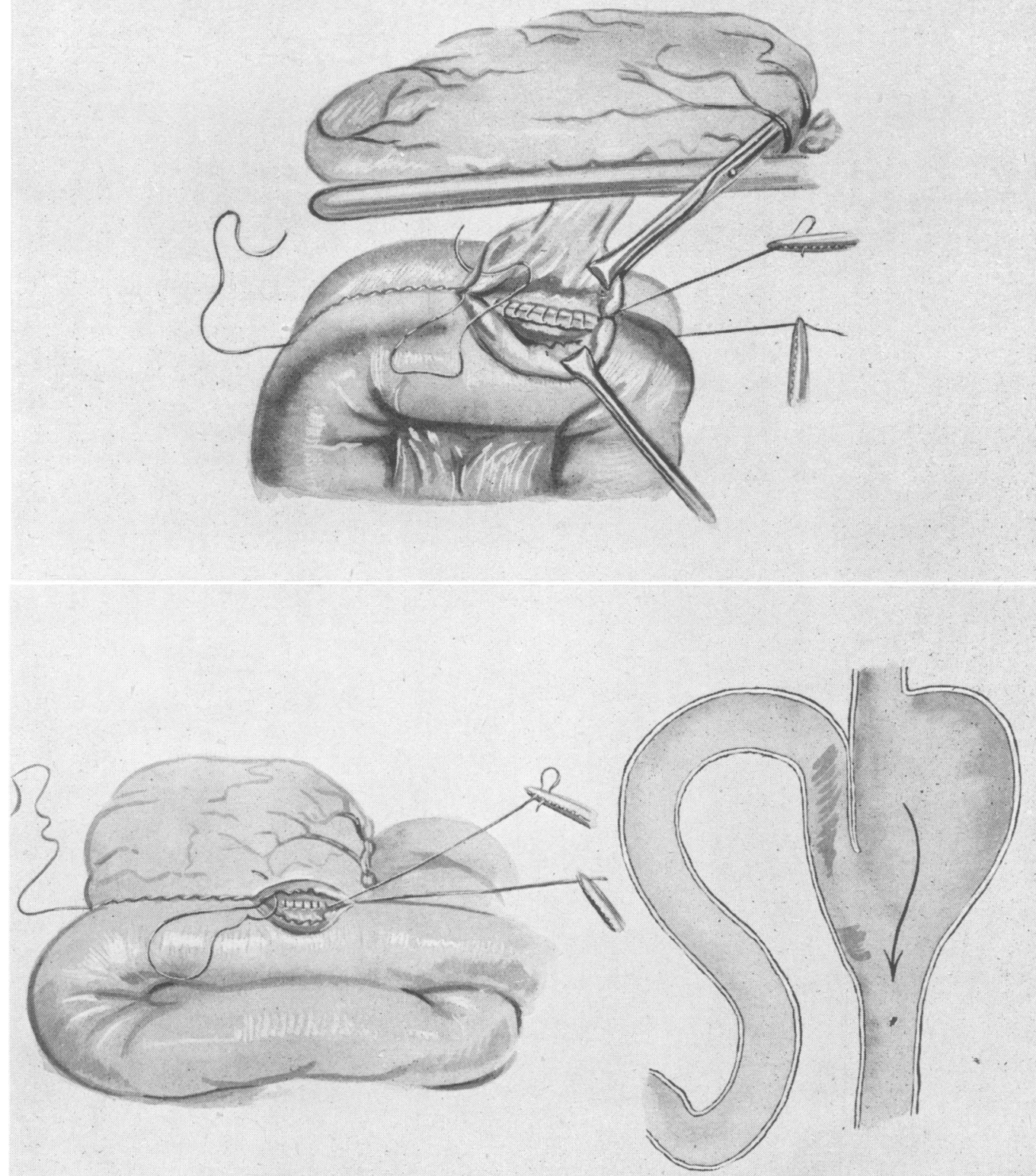

Fig. II.-Polya-Hofmeister Subtotal Gastrectomy. The first anterior continuous suture is introduced as a Schmieden in-out in-out stitch. Note how the Payr clamp exerts upwards traction and facilitates the introduction of the sutures.

Fig. 12.-Polya-Hofmeister Subtotal Gastrectomy. After the stomach has been cut adrift the first anterior continuous suture is continued towards the greater curvature, and then tied to the end which has been left long.

FIG. 13.-Polya-Hofmeister Subtotal Gastrectomy. Diagram showing the graceful lax, S-shaped, afferent, jejunal limb, the position of the valve, the funnel-shaped gastric pouch, and the site of the stoma. All nourishment is thereby deflected into the efferent limb of jejunum and none can find its way into the duodenum. 
When resection is considered too hazardous, the ulcer should be exposed by an ample incision through the anterior duodenal wall and pyloric sphincter, the edges of the wound held apart with Allis forceps, and four cross mattress sutures of strong silk be inserted deeply through the edges and base of the ulcer and tied very tightly.

This controls the bleeding, obliterates the ulcer, and is, in my opinion, the most efficient emergency method of dealing with the bleeding artery.

The wound in the anterior wall of the duodenum and pylorus is then closed transversely, but if, owing to the scarred condition of the bowel wall, this is not possible, then the adjacent edges of stomach and duodenum are approximated with a three-tier suture and protected with an omental graft.

(c) Scar Stenosis due to Long-Standing Duodenal Ulcer and Chronic Penetrating Ulcer. Here the choice of operation is gastro-jejunostomy or gastric resection. About I 5 per cent. of all cases of chronic duodenal ulcer referred to me are eventually subjected to operation, and some 80 per cent. of these undergo resection by the PolyaHofmeister technique. The so-called irremovable duodenal ulcer is treated by Bancroft's method plus subtotal gastrectomy, whilst gastro-jejunostomy is reserved for those who are obviously incapable of withstanding a major surgical procedure.

\section{(4) The Technique of the Operations}

(a) Gastro-jejunostomy. As previously stated, the indications for this operation are as follows : (i) Pyloric stenosis due to cicatrizing duodenal ulcer associated with achlorhydria or hypochlorhydria in patients over the age of 60 ; (ii) aged and feeble patients with obstructive symptoms or severe pain due to a decply penetrating ulcer ; (iii) poor general condition of the patient due to some concomitant disease rendering gastric resection too hazardous.

The posterior operation is in almost every respect superior to the anterior method of anastomosis. Nevertheless, if the first loop of jejunum is firmly anchored to the under-surface of the mesocolon, or if there are numerous congenital bands or adhesions present in this situation, it may be unwise to dissect them free in order to facilitate the performance of a posterior gastro-jejunostomy. In such cases I am convinced that the anterior operation is preferable.

Again, the posterior operation may be contraindicated if the mesocolon is unduly laden with fat, or the middle colic artery or its arching branches pursue an anomalous course or are impossible to visualize, if numerous large ramifying blood vessels occupy the mesocolon and no suitable space remains between them through which the stomach or jejunum may be drawn, or where the mesocolon is unduly stunted or adherent to the stomach bed.

In the posterior operation, if the stomach is large or dilated as the result of obstruction to its outlet, it is best to make the stoma vertical, i.e., from the lesser curvai ire near the incisura to the lowest point of the greater curvature. If, however, the stomach is small and contracted, a longitudinal stoma, 3 in. long, placed near the greater curvature but on the posterior wall of the stomach, is preferable. A satisfactory longitudinal stoma should be about $\frac{1}{2}$ in. away from and parallel with the greater curvature, and should be evenly bisected by an imaginary line dropped from the lesser curve of the stomach ; in other words, it should be situated at the most dependent portion nf the stomach.

The stoma when completed should easily admit three fingers. The portion of proximal jejunum for the anastomosis should be chosen with the greatest care. If the stomach is ptosed, a long loop (8ro in.) will be necessary; but if the organ is of the steerhorn type and lies high up in the epigastrium, a short loop (5-6 ins.) will suffice.

The opening in the mesocolon through which the selected fold of stomach is drawn is made to the left of the main branch of the middle colic artery, and the edges of the mesocolon are sutured to the stomach wall before the anastomosis is commenced.

Most surgeons follow the practice of Moynihan and the Mayos and prefer to use large guarded clamps and two continuous sutures when carrying out the anastomosis. The writer usually performs gastro-jejunostomy without the aid of clamps, as spillage does not occur when the gastric contents are aspirated before and during the operation; bleeding can with assurance be controlled by well-placed sutures, and the procedure is relatively atraumatic. The method whereby three continuous sutures are used is depicted in Fi. . 15. This is the one usually employed by the writer.

Lately, when performing anterior gastrojejunostomy, I have adopted Lahey's plan (1944) of detaching the vascular gastro-epiploic arch from the pylorus to a point 3 in. or so from the lower pole of the spleen, and of removing the related great omentum after it has been snipped free from its filmy attachment to the transverse colon. With the omentum out of the way, the field is clear and a relatively snort loop of proximal jejunum averaging about 8 in. can be drawn across the bared transverse colon for anastomosis to the posterior aspect of the stomach near the greater curvature. The stoma (which should be at least $2 \frac{1}{2}$ in. long 
and bisected by the imaginary line produced downwards from the right border of the lesser curvature) should be situated $\frac{1}{2}$ in. from the greater curvature and parallel with it, and must in all cases be at the most dependent part of the stomach. There must be no compression of the transverse colon or kinking or traction at the duodenojejunal flexure or at the points where the proximal and distal limbs of the jejunum are stitched to the stomach. The operation is performed without the aid of clamps, and three continuous sutures are employed, as in making the posterior anastomosis (Fig. 15).

(b) Subtotal gastrectomy by the Polya-Hofmeister method. The anterior or ante-colic long-loop method is chosen in preference to the posterior operation for the reasons previously stated, and if the first portion of the duodenum containing the ulcer can with safety be freed and excised and its distal end soundly inturned without any risk of leakage or of compromising the lower reaches of the common bile duct, this should be performed unhesitatingly.

When, on the other hand, the duodenum is fixed to the pancreas by a deeply penetrating ulcer and inflammatory adhesions, the crater has burrowed its way into the precincts of the bile duct, or the involved sclerotic bulb is so inaccessible that dissection and excision of the first part of the duodenum would prove too hazardous an undertaking, the distal transection should be carried out through the antrum and the operation be completed on the lines suggested by Bancroft (1932).

Most of the deaths which follow partial or subtotal gastrectomy for duodenal ulcer are due to unnecessary, highly dangerous and protracted dissections of the first portion of the duodenum, or to the surgeon being misguided into believing that the cartilagenous-like scarred and fused bulb is a stenosing pyloric carinoma, which must be amputated at all costs.

It is, nevertheless, true that with practice and painstaking dissection most chronic duodenal ulcers can be excised, or at least the first portion of the duodenum can be cleared, divided, and closed in a watertight fashion even if the crater is left behind embedded in the substance of the pancreas.

It is important to close the duodenal stump very securely with at least two rows of unabsorbable suture material, and if there is any doubt about the integrity of the suture line, the area should be drained with a Penrose or corrugated rubber tube through a stab incision in the flank.

As most duodenal ulcers seen at operation are posterior and superior, i.e., involve the posterior wall and the lesser curvature of the duodenum, and as with such lesions the right margin of the gastro-hepatic omentum is usually contracted and $\frac{\mathbb{Q}}{\mathbb{D}}$ of leathery consistency, the dissection and isolation $\stackrel{\varrho}{c}$ of the right gastric artery should be carried out $\stackrel{\hookrightarrow}{\Rightarrow}$ cautiously and with due respect to the common bile duct, and to the main branch of the hepatic arteryo which may be drawn downwards by dense 음 adhesions.

In most cases I now display the common bile $\underset{\Omega}{\overparen{\Phi}}$ duct and ascertain the relations of the ulcer to the duct. Sometimes the common bile duct is opened ${ }^{\text {s }}$ and a Bakês dilator is passed into the duodenum, or. again one limb of a large T-tube may be intro- $\vec{\overrightarrow{ }}$ duced through the opening in the choledochus and ${ }^{\omega}$ then on through the papilla so that the duct cand be seen and felt during the dissection of the ulcer 3 . from the pancreas. If the duct is opened fori probing or the passage of a sound, it is always $\dot{\sim}$ drained by means of a T-tube. The T-tube is re- 8 moved on the seventh post-operative day.

The operation is planned for acid reduction, $\vec{\omega}$ hence nothing short of subtotal resection of the 을 organ will suffice. Pylorectomy, hemi-gastrec- tomy and partial gastrectomy, whether for cancer 3 or for ulcer, are operations of a former decade.

I have learned that it is not necessary to pre- $\stackrel{-}{-}$ serve the vascular epiploic arch intact. The blo@i $\overrightarrow{0}$ vessels in the great omentum do not become farcted nor does gangrene of this structure supep-:vene when the arteries below the arch are ligatured and divided.

The mortality of subtotal gastrectomy for chronic duodenal ulcer is low. At the Mayo $\mathbb{Q}$ Clinic during I943 no fewer than I9I cases were $\overrightarrow{\vec{P}}$ subjected to this operation, and only one patient $\frac{O}{3}$ died (from pulmonary embolism). In 1945, 24I cases were treated by gastric resection with fouro deaths (I.7 per cent.).

In the hands of a skilled and careful surgeon 3 . working under the best conditions, the death-rate following gastric resection for duodenal ulcer should not exceed 3 per cent.

(c) Bancroft's procedure. This operation is employed for the irremovable duodenal ulcer. It 음 consists in making a circular incision through the $>$ seromuscular coats of the antrum about three? finger-breadths above the pyloric sphincter, andN dissecting the pyloric mucous membrane free to a point where it is embraced by the muscular
ring.

The separation of this cuff of mucous membrane? from its seromuscular sheath should be conductedo daintily and cautiously, and more especially as the dissection proceeds towards the sphincteric ring. where the membrane is soft, oedematous and friable. Any fissuring or tearing of the lining of the pyloric canal itself might be followed by serious? consequences-leakage, abscess, peritonitis, $\stackrel{\mathbb{D}}{\circ}$ duodenal fistula, etc. 
A purse-string suture of No. 00 medium chromic catgut, which picks up only the submucosal coat, is passed around the unopened tube of mucous membrane close to the pyloric sphincter, after which the mucous membrane is cut away between haemostats. The haemostat near the pursestring suture is removed and the crushed mucous rim is immediately invaginated as the pursestring suture is drawn taut. The tube of mucous membrane should not be ligated and then cut away, as leakage is likely to ensue (Fig. I6(3)). One or two other purse-string sutures placed on the exposed pyloric muscle complete the closure. The superfluous seromuscular sheath is trimmed down and its margins drawn together with a sewingmachine stitch, and the stubby end of the pylorus smothered in omentum. No dead spaces should be allowed to remain between the invaginated stump of mucous membrane in the pyloric canal and the freed seromuscular sheath. The operation is completed by performing an ante-colic Polya-Hofmeister subtotal gastrectomy after the manner already described.

Some years ago Finsterer advocated transection of the antrum and distal closure followed by gastric excision for these irremovable ulcers of the duodenum. The late results of the operation are bad ; jejunal ulceration is a common sequel, as Ogilvie (1938) and others have shown; it leaves behind in the pyloric mucous membrane an agent of evil-a hormone which stimulates the principal glands to pour out pepsin and hydrochloric acid, while the stump occasionally blows out when the secretions generated in the antral mucous membrane cannot escape through a strictured duodenum. This operation should, therefore, never be practised.

On the other hand, Bancroft's procedure leads in time to complete healing of the ulcer, which is constantly bathed in alkaline juices and freed from the irritating breaking-down products of digestion. The ulcer heals rapidly and in time the first portion of the duodenum becomes free and detached from subjacent pancreas. In a personal series of 88 cases treated by Bancroft's method there were two deaths-both from peritonitis.

Drainage of the right subhepatic space is carried out as a routine procedure after Bancroft's operation, when T-tube drainage of the common bile duct has been performed, and also following all those cases in which there is any doubt about the effective closure of the duodenal stump.

(d) Vagotomy. Vagotomy, or gastric neurectomy by the transthoracic or abdominal route, is an interesting and fascinating lesson in human physiology. It is too early as yet to speak of late results or of what place this operation is destined to take in the treatment of duodenal ulcer or of gastro- jejunal ulcer. At the present time $I$ reserve $\frac{3}{\mathbb{D}}$ abdominal gastric neurectomy for the following $\stackrel{\varrho}{c}$ types of cases : (i) Young patients with uncomplicated lesions in whom repeated and prolonged $\stackrel{\vec{F}}{\stackrel{9}{+}}$ treatment in hospital has failed to effect a cure ; $\bar{C}$ (ii) patients under the age of 60 with chronic duodenal ulcer in whom gastric resection is $\frac{\bar{\omega}}{\vec{D}}$ deemed too hazardous. Here the vagotomy is $\stackrel{\varnothing}{\varrho}$ combined with gastro-jejunostomy; and (iii) those cases of gastro-jejunal ulcers which have $\overrightarrow{0}$ followed in the wake of a well-performed subtotal gastrectomy.

I do not advise transthoracic vagotomy for (iii) as I believe that by the abdominal route large segments of the right and left vagus nerves can be 3 . resected after the surgeon has assured himself that the amount of stomach removed is adequate, that the stoma is well placed and that a gastro-jejuno- 8 colic fistula can be excluded with safety. I would $\overrightarrow{\vec{A}}$ not now perform vagotomy plus $\wedge$ gastro- $\omega$

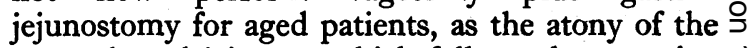
stomach and jejunum which follows the resection of the vagus nerves in such patients may last for several weeks or even months.

Some of my patients have experienced a number of ill-effects following vagotomy, including ing tractable diarrhoea, the frequent belching of mals dorous gases, and prolonged retention. Duriris the last 18 months I have performed this operation on 36 patients, and my experience would lead me to suggest that we should reserve this operation strictly for the types of cases I have mentioned above.

The reader is referred to the writings on this subject by Dragstedt, who has now a series of cases dating back to r 943 , to Allen's Moynihan Oration (1947), and to Walters' valuable and instructive paper in the 'Proceedings of the Staff: Meetings of the Mayo Clinic' (22, 281, 1947).

\section{Comments on Other Operations for Duodenal Ulcer}

Horsley's pyloroplasty (1919), Judd's pyloro- 을 plasty (I922), Jaboulay's gastro-duodenostomy $\frac{7}{0}$ (1892), and Finney's gastro-duodenostomy (1902) are all inferior to a well-performed gastro- $N$ jejunostomy and are seldom practised to-day.

The Billroth I operation, however, is popular in N certain clinics and has many able exponents. When $\omega$ employed in the treatment of chronic duodenal ulcer it is open to the following objections :

I. The surgeon, unless he is experienced in the performance of this method, is often more concerned about an easy approximation of the cut end of the stomach to the cut end of the duodenum than with a wide resection of the stomach.

2. As a result of long-standing ulceration, the $\stackrel{\square}{\square}$ duodenum may be shortened, distorted, and the 
seat of a widespread duodenitis. Again, even when it can be mobilized, the part which remains after the removal of the ulcer-bearing area, together with the surrounding zone of inflammation, is always short, inaccessible and difficult to approximate to the small gastric pouch, while end-to-end union may be, and often is, a tedious and anxious undertaking in such circumstances.

3. When the anastomosis is completed, the parts often appear fixed, tense and strained, a state of affairs incompatible with sound healing and sound functioning.

4. The duodenum is a thin-walled friable structure and quite devoid of peritoneum on its posterior surface, and it is for these reasons that extraordinary precautions are taken when fashioning the stoma to prevent leakage, peritonitis, the production of a valve, or extreme narrowing of the new opening.

5. The late results are by no means so satisfactory as when the Polya-Hofmeister procedure is employed.

\section{Conclusions}

I. The chief indications for operation in cases of chronic duodenal ulcer are :

(a) Acute perforation.

(b) Uncontrollable bleeding.

(c) Pyloric obstruction due to a stenosing lesion.

(d) Intractability-failure to respond to medical treatment.

2. The operation of choice is the ante-colic Polya-Hofmeister subtotal gastrectomy. Bancroft's procedure is reserved for the irremovable duodenal ulcer. Vagotomy, promising as it appears to be, is as yet under trial.

3. Gastro-jejunostomy should be chosen in preference to gastric resection for aged and infirm patients, and for elderly patients with pyloric stenosis associated with low acid values in the gastric juice, and for those who, owing to some debilitating condition, are considered to be poor operative risks.

4. The pre-operative preparation of these patients has been a great factor in lowering mortality-rate which is now under 3 per cent.

\section{BIBLIOGRAPHY}

BABCOCK, W. W. (1942), Surg., Gynec. and Obst., 75, 485. COUNSELLER, V. S., WAUGH, J. M., and CLAGETT, O. T. (1944), Proc. Staff Meet. Mayo Clinic., 19, 569.

CULLIGAN, L. C. (1944): Surg., Gynec. and Obst., 79, 629.

FINNEY, J. M. T. (1902), Bull.' Fohns Hopkins Hospital, 13, 155.

FINOCHIETTO, E. (1936), Post-Graduate Surgery (Ed. R. Maingot), 1,526

FINSTERER, H. (1934), Rev. de Chir., 72, 511 .

FINSTERER, H. (1918), Zentrabl. f. Chir., 26, 434.

FREEMAN, H. (1944), Brit. F. Surg., 32, 303 .

GRAHAM, ROSCOE'R. (1937), Surg. Gynec. and Obst., 64, 235.

HOLMES, G. W., and HAMPTON, A. O. (1932), Y.A.M.A., 99,

HORS'.

JUDD, E. S. (1922), $\mathcal{F}$. Lancet., 42, 381,
LAHEY, F. (1944), Surg., Gynec. and Obst., 78, 169.

MAINGOT, R.' (1940), 'Abdominal Operations,' AppletonCentury Co.

MAINGOT, R. (1941), ' Technique of Gastric Operations,' Oxford Univ. Press.

MAINGOT, R. (1942), Post Graduate Medical Ұ., 18, 93.

MATTHEWS, W. B. (1935), Ann. Surg., 101, 844

MORLOCK, C. G. (1944), Proc. Staff. Meet. Mayo Clinic, 19, OGILVIE, W. H. (1938), Lancet, $2,295$.

PANNETT, C. A. (1938), Surg., Gynec. and Obst., 67, 495

PANNETT, C. A. (1924), Brit. F. Surg., 12, 273.

PANNETT, C. A. (1945), Brit. $\mathcal{F}$. Surg., 32, 418.

POLYA, E. (1911), Zbl. f. Chir., 38, 892.

SIPPY, B. W. (1915), F.A.M.A., 64, 1625 .

WANGENSTEEN, O. H. (1940), Surg., Gynec. and Obst., 70, 58.

WANGENSTEEN, O. H. (1937), $\mathcal{F}$. Lancet, 57, 1 .

WANGENSTEEN, O. H. (1941), Surg., Gynec. and Obst., 72, 257.

\section{Scheme of Nursing for Subtotal Gastrectomy Cases}

Most cases are admitted to surgical wards seven days before operation.

Seven to three days before operation: Strict medical treatment ; correct anaemia and dehydration ; gastric aspiration and lavage to relieve any obstructive symptoms ; attention to bowels ; ensure sound sleep at night; give vitamins A, B and $\mathrm{C}$ in full dosage.

Two days before operation : Diet, Meulengracht I. Paraffin $\frac{1}{2}$ oz. b.d. ; soap enema. Continue vitamin treatment; sleeping draught at night; pass a Ryle tube through nostril into the stomach and aspirate gastric contents, after which irrigate with warm saline solution.

One day before operation: Same as above. Shave abdomen and pubic region, wash with ether soap, and paint with euflavine-alcohol; apply. dry dressing.

Day of operation: From 12 midnight give clear fluids only by mouth. Pass Ryle tube, wash out stomach, leave tube in situ, fixing end of tube to cheek, and insert wooden spiggot.

On return from operating room : Shock treatment (if required); raise end of bed on blocks ; give intravenous glucose-saline, plasma, serum or blood transfusion. Omnopon gr. $\frac{1}{3}$ when fully recovered from anaesthetic, and then omnopon gr. $\frac{1}{6}$ six-hourly; $\mathrm{O}_{2}$ by B.L.B. mask for five minutes hourly (whilst awake) ; 'stir-up' treatment-make patient sit up in bed, breathe deeply, and cough hourly, change his position in bed frequently and move arms and legs 1,000 times daily. Using a $20 \mathrm{cc}$. Record syringe, aspirate the Ryle tube two-hourly, and occasionally irrigate the stomach with $20 \mathrm{cc}$. of warm saline ; the Ryle tube is left in situ for about $36-48$ hours; the patient is allowed to drink as much as two to three pints of clear fluids during the first 24 hours after operation. Keep a 24-hour intake and output chart; keep an hourly pulse chart until pulse settles down below 80 ; examine the urine daily. Give penicillin $25^{\circ}, 000$ units intramuscularly sixhourly for four days. 

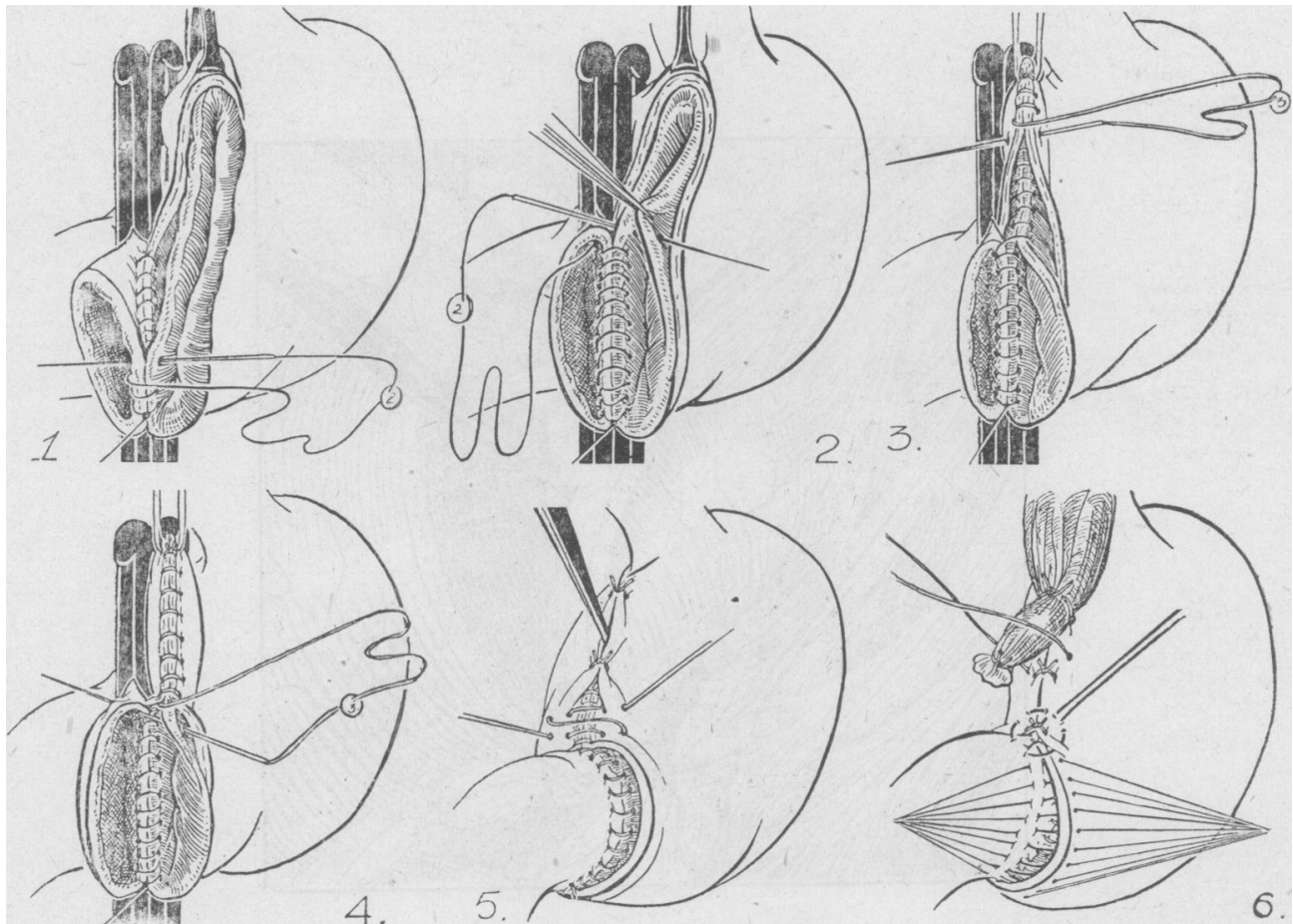

6

Fig. 14.-Finochietto's Billroth I. Technique. The most important steps of the anastomosis of the cut ends of the stomach and duodenum are depicted.

(From Maingot's 'Abdominal Operations.' By courtesy of Appleton-Century.)
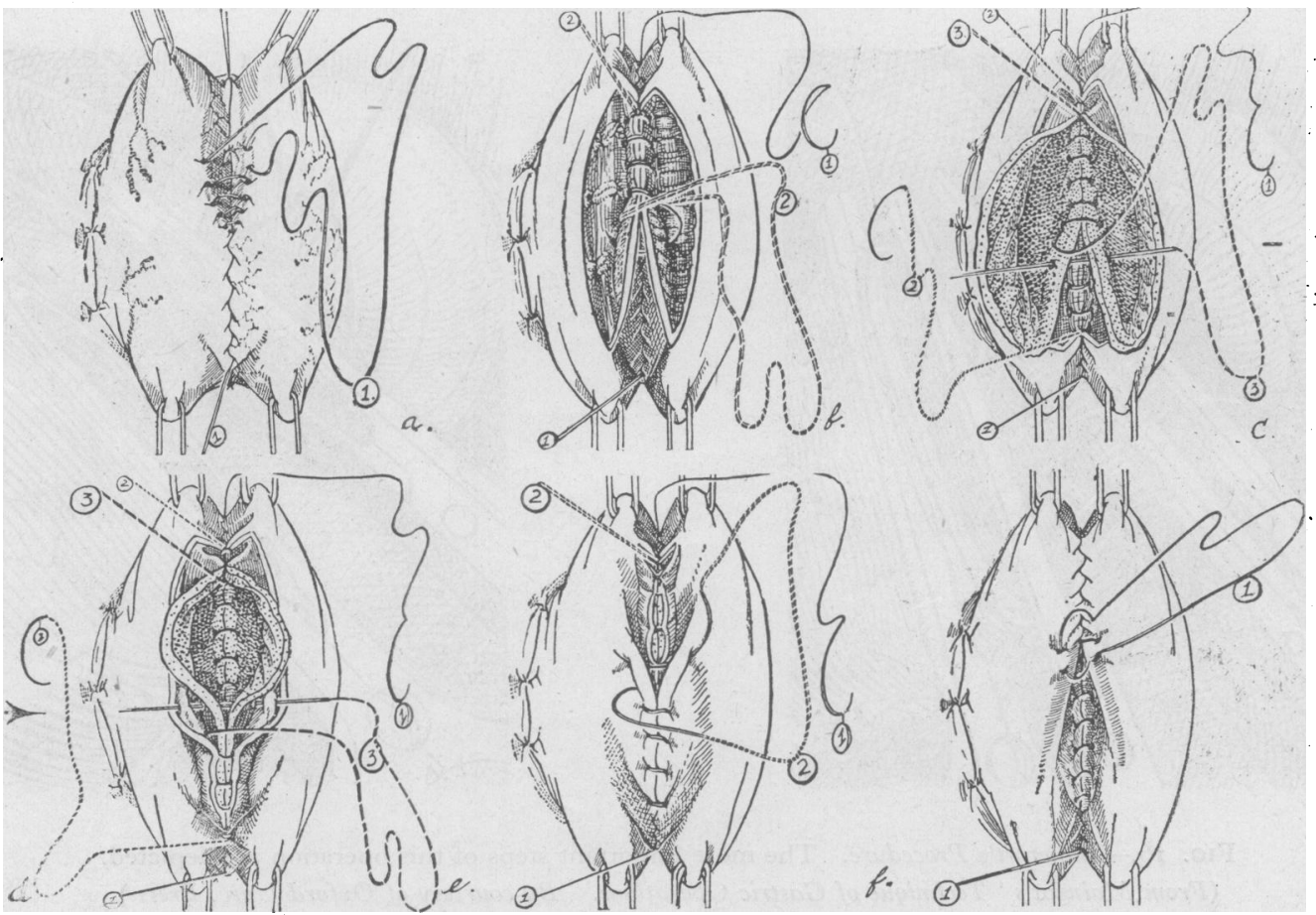

Fig. 15.-Gastrojejunostomy. The three continuous-suture method is shown step by step.

(From Maingot's 'Technique of Gastric Operation.' By courtesy.of Oxford Univ. Press.) 


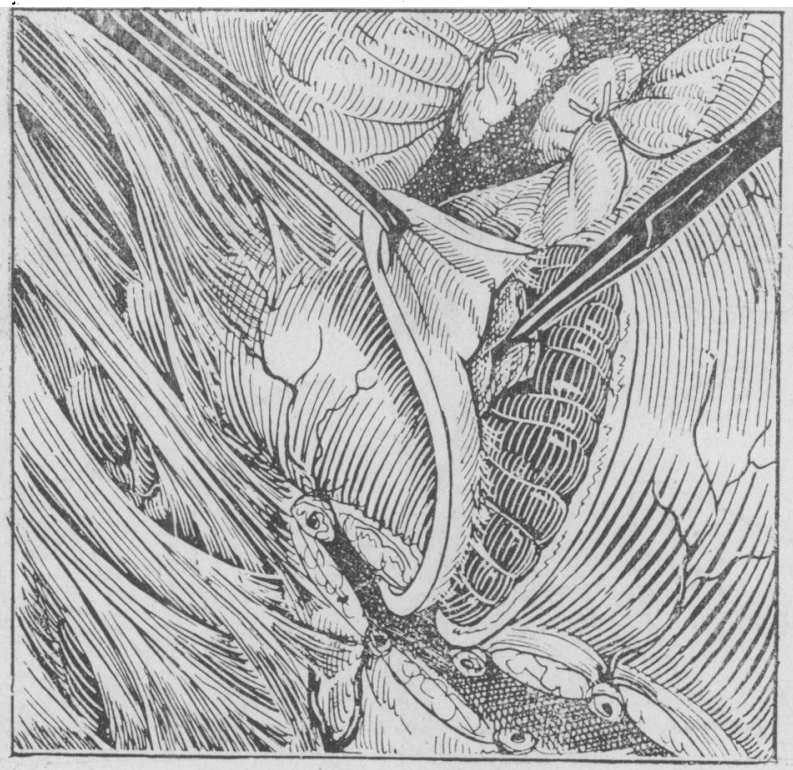

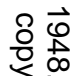

흥.
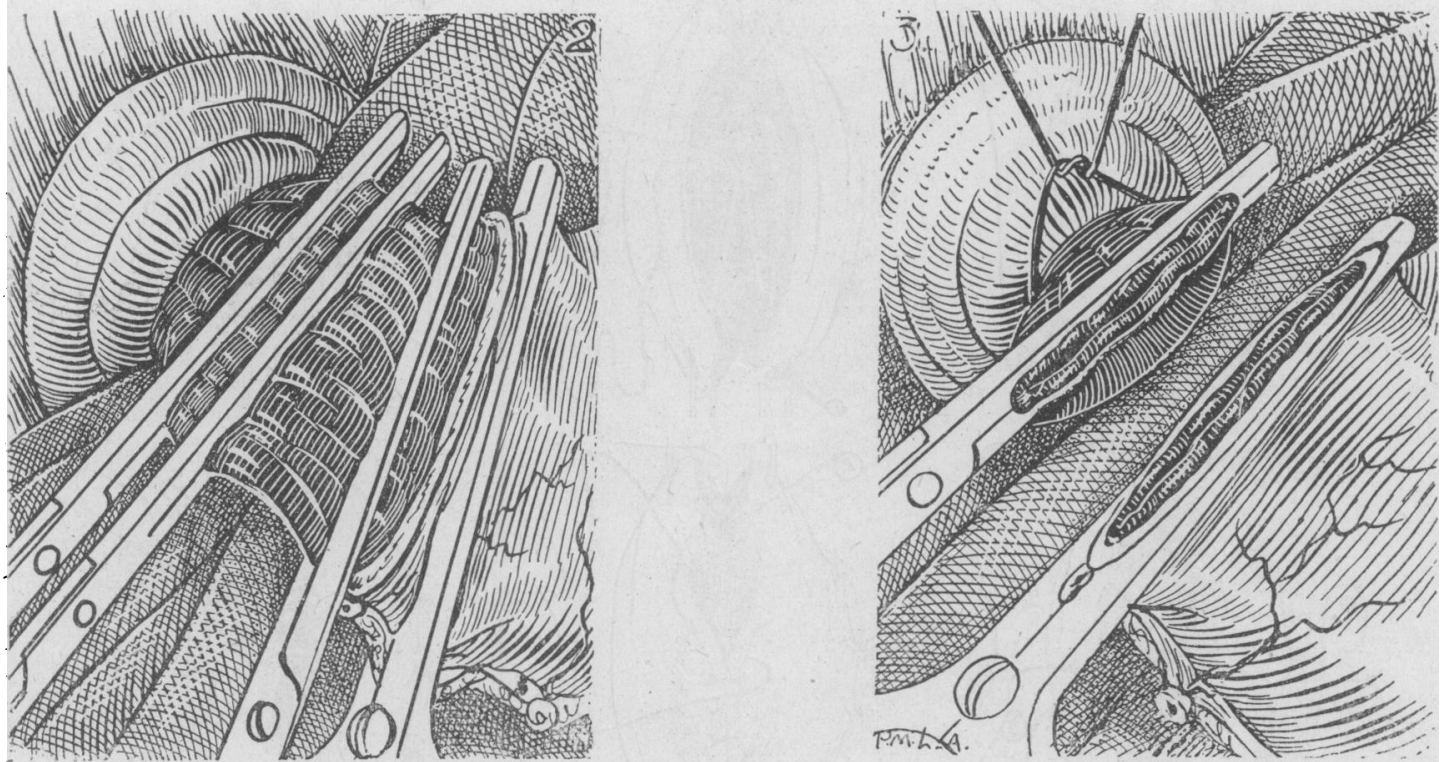

Fig. 16.-Bancroft's Procedure. The more important steps of this operation are depicted.

(From Maingot's 'Technique of Gastric Operations.' By courtesy of Oxford Univ. Press.) 


\section{DIET FOR GASTRIC PATIENTS}

\section{Modified Meulengracht}

\begin{tabular}{|c|c|c|c|}
\hline \multicolumn{2}{|r|}{ (I) } & \multirow[b]{2}{*}{ As No. 1.} & \multirow[b]{2}{*}{ As No. $\mathrm{I}$. } \\
\hline 6 a.m. & $\begin{array}{l}\text { 3-5 oz. sweetened flavoured } \\
\text { milk. }\end{array}$ & & \\
\hline 8 a.m. & $\begin{array}{l}\text { 3-5 oz. milk and one beaten } \\
\text { egg. }\end{array}$ & $\begin{array}{l}5 \text { oz. milk, one egg lightly boiled or } \\
\text { poached. Thin crustless bread } \\
\text { and butter ( } 2 \text { slices). }\end{array}$ & $\begin{array}{l}\text { One egg lightly boiled or poached, } \\
\text { or white fish baked in milk or } \\
\text { steamed. Thin crustless bread (3 } \\
\text { slices) and butter. Very weak } \\
\text { milky tea. }\end{array}$ \\
\hline ro a.m. & $\begin{array}{l}\text { 3-5 oz. sweetened flavoured } \\
\text { milk. }\end{array}$ & As No. $\mathrm{r}$. & As No. I. \\
\hline I 2 noon. & $\begin{array}{l}\text { Pounded fish or } 3 \text { oz. minced } \\
\text { and pounded sweetbreads } \\
\text { or brains or chicken. } 2 \frac{1}{2} \\
\text { mashed potatoes, } 2 \text { tb.sp. } \\
\text { Sieved vegetables, } 2 \text { tb.sp. } \\
\text { Milk pudding, custard or } \\
\text { jelly. Av. serving. }\end{array}$ & $\begin{array}{l}\text { Steamed or baked fish, } 4 \text { oz., and } \\
\text { sauce, or as No. I. Mashed } \\
\text { potatoes, } 2 \text { tb.sp. Sieved veget- } \\
\text { ables, } 2 \text { tb.sp. Milk pudding, } \\
\text { custard or jelly. Av. serving. }\end{array}$ & $\begin{array}{l}\text { As No. I and } 2 \text {, or minced lamb or } \\
\text { mutton, } 3 \text { oz., or minced rabbit. } \\
\text { Mashed potatoes, } 3 \text { tb.sp. Sieved } \\
\text { vegetables, } 2 \text { tb.sp. Milk pud- } \\
\text { ding, custard or jelly. Av. serving. }\end{array}$ \\
\hline 2 p.m. & $\begin{array}{l}\text { 3-5 oz. sweetened flavoured } \\
\text { milk. }\end{array}$ & As No. $\mathrm{r}$. & As No. $\mathrm{r}$. \\
\hline 4 p.m. & $\begin{array}{l}\text { 3-5 oz. milk and one beaten } \\
\text { egg or sieved fruit. Milk } \\
\text { jelly, custard or trifle or } \\
\text { junket. }\end{array}$ & $\begin{array}{l}5 \text { oz. milk. One egg lightly boiled } \\
\text { or poached, or sieved fruit. Thin } \\
\text { crustless bread and butter ( } 2 \\
\text { slices). Milk jelly, custard, trifle } \\
\text { or junket. }\end{array}$ & $\begin{array}{l}\text { Very weak milky tea. Then as } \\
\text { No. } 2 \text {. }\end{array}$ \\
\hline 6 p.m. & $\begin{array}{l}\text { 3-5 oz. sweetened flavoured } \\
\text { milk. Milk pudding. }\end{array}$ & As No. 1. & As No. 1. \\
\hline 8 p.m. & $\begin{array}{l}\text { 3-5 oz. sweetened flavoured } \\
\text { milk. }\end{array}$ & As No. $\mathrm{I}$. & As No. 1. \\
\hline During $N$ & ights. $7 \mathrm{oz}$. milk if awake. & As No. 1 . & As No. I. \\
\hline
\end{tabular}

To flavour milk use Ovaltine, Bengers, Horlicks or Bourn-vita.

All vegetables are cooked, minced and sieved.

Fish, sweetbreads, tripe and brains for No. I diets are minced and pounded and mixed with white sauce.

Milk pudding as follows : Rice, sago, tapioca, ground rice, chocolate blancmange, vanilla blancmange (with custard powder), semolina, using strained fruit juice to flavour when possible.

Approximate caloric value :

$$
\begin{array}{llllllll}
\text { No. } 1 & . . & . . & . . & . . & . . & . . & \mathbf{1}, 500 \\
\text { No. } 2 & . . & . . & . . & . . & . . & . . & \mathbf{1}, 000 \\
\text { No. } 3 & . . & . . & . . & . & . . & . .2000
\end{array}
$$
cases.

The above schemes of nursing and diets for gastric cases are subject to alterations and modifications in individual 
First day after operation: Induce patient to drink two to three pints of clear fluids and weak tea ; stomach aspirations two-hourly ; continue stir-up treatment. Omnopon gr. $\frac{1}{6}$ p.r.n. for pain, if required. Ensure sound sleep at night by means of Soneryl, Seconal, Amytal or Medinal. Recommence vitamin treatment and continue for ten days. Get patient out of bed for short time.

Second day after operation : Ryle tube removed about $36-48$ hours after operation; after removal of Ryle tube patient has only sips of clear fluid for first six hours, and after that $4 \mathrm{oz}$. hourly. Continue deep breathing exercises.

Third day after operation : Give $4 \mathrm{oz}$. hourly of water, barley water, glucose water, Bovril, weak tea, fruit juices, etc. ; sweets ; paraffin I oz. b.d. by mouth ; continue vitamins and sedative drugs for a few more days. Allow patient out of bed for a short while every day.
Fourth day after operation: Increased feeds ; jellies, junkets, custards, blancmanges, eggs, $\frac{\bar{D}}{\mathrm{D}}$ paraffin I oz. b.d. Insert two glycerine suppositories ; if no result give soap or olive oil and $\stackrel{.}{\Rightarrow}$ paraffin enema.

Fifth and sixth days after operation : Meulen- $\frac{+}{0}$ gracht I diet. Skin stitches removed. Paraffin 듬 I oz. b.d. ; glycerine suppositories or enema if $\frac{\bar{c}}{\frac{\rho}{5}}$ required.

Seventh to tenth day after operation : Meulengracht II or III according to condition of patient. क After the tenth day the patient is put on full diet $\vec{\circ}$ and given a tonic mixture containing iron and $\overrightarrow{\vec{H}}$ arsenic.

\section{Meulengracht Diets}

Weak tea, fruit juice, glucose water or barley water may be substituted for milk drinks in the Meulengracht I Diet Scheme.

\section{BOOK REVIEWS}

\section{GANGER OF THE BREAST}

By D. C. L. Frtzwilliams, C.M.G., M.D., Ch.M., F.R.C.S. William Heinemann Medical Books Ltd. 1947. Pp. 199 with 20 plates. Price 25s.

This book appears opportunely when considerable interest is being revived in more conservative operative procedures, associated with radiotherapy, for the treatment of carcinoma of the breast. The author has spent much of his life treating this disease and he illustrates his text with a great number of case records which add weight to his argument.

He divides the disease into the four stages, primary growth, lymphatic spread, floating cell and metastasis. He proceeds to discuss the spread of the tumour laying stress on the blood stream as a vehicle for carcinoma cells. The chapter devoted to early diagnosis is excellent and the case histories appended, illustrating the mistakes made by the practitioner and surgeon, are very instructive. The use of transillumination in investigating a tumour in the breast is described as the surest and earliest method in the hands of those who are familiar with it.

Treatment by local removal, radical operation and radium is described in detail and illustrated by photographs. Stress is laid on the value of radiotherapy and much valuable information is provided as to what can and cannot be expected from radium and $\mathrm{X}$-rays.
There is an additional chapter by Miss Alice Ross on the principles of X-ray therapy in both operable and inoperable mammary carcinoma. The index is deplorable and quite unworthy of the book.

This is a valuable and stimulating addition to the surgeon's library on carcinoma of the breast.

S.F.T.

\section{THE TREATMENT OF SOME GHRONIG AND} INGURABLE DISEASES

By A. T. Todd, O.B.E., M.B., Ch.B., M.R.C.P. and Edition. John Wright \& Sons, Ltd. Pp. 324. 1947. Price 25s.

The reviewer finds himself in disagreement with many of the author's views. Dr. Todd believes that 'duodenitis ' produces poor respiratory movements and thus inadequate return of blood to the heart; the inadequate venous return leads, we are told $N$ (p. 145), to inadequate aortic pressure-coronary 0 disease and myocardial degeneration. Later (p. 156) $\widetilde{O}$ however, he tells us that inadequate venous return $\underset{\mathrm{G}}{\mathrm{G}}$ leads to hyperpiesia. His explanation of dysmenorrhoea on the basis of faulty fat metabolism producing faulty sterols and so faulty oestrins and luteins (p. 136) is typical of the hypotheses with which the book abounds.

Dr. Todd's theory of diabetes is that the disease (like many others) is due to hepatic dysfunction, and that insulin is to be avoided except to rescue the patient from the diabetic coma into which he has 